\title{
Asthma deaths in England and Wales 1931-85: evidence for a true increase in asthma mortality
}

\author{
PETER BURNEY \\ From the Department of Community Medicine, United Medical and Dental Schools of Guy's and St Thomas' \\ Hospitals (St Thomas' Campus), London SE1 7EH
}

SUMMARY A recent increase in asthma mortality has been reported in several countries. Such increases can be brought about by changes in factors acting close to the time of death, but they may also be caused by risk factors determined by the generation into which a person is born, as indicated by the year of birth. Asthma mortality rates since 1931 are independently associated with birthdate as well as date of death. In particular there has been an increase in asthma mortality in birth cohorts born since the 1940s. Such changes are unlikely to be due to a change in reporting of asthma deaths, and other evidence including the reported increase in the prevalence of eczema in succeeding National Birth cohorts supports the view that these changes may be due to an increased prevalence of atopy. In the absence of any further improvements in the management of asthma, such an increased prevalence of atopy implies that the mortality rate is unlikely to decline substantially for some years to come.

A recent increase has been reported in asthma mortality in England and Wales ${ }^{1-3}$ though the importance of this increase has also been questioned. ${ }^{4-6}$ The official mortality statistics show a $50 \%$ increase in recorded mortality from asthma among 5-34 year olds between 1974 and $1984,{ }^{2}$ an increase that is not due to the change in the ICD codes in 1978-9. ${ }^{2}$ It has been argued that the previous high death rate in the 1960 s removed susceptible asthmatics from the population, leading to an artificially low death rate in the early 1970 s and to an inevitable increase in mortality as the susceptible population was re-established. But as the increase was seen most markedly in an age group unaffected by the previous epidemic, this explanation is unconvincing. ${ }^{5}$ Similar increases in mortality in France, Denmark, Germany, ${ }^{7}$ New Zealand, ${ }^{8}$ and the United States ${ }^{9}$ make it less likely that these increases are due to local changes in the way cause of death is assigned.

Because asthma seems so amenable to treatment, death from asthma has been used as a sentinel event to mark a failure in the health services. ${ }^{10}$ Yet although prescriptions of specific and effective drugs for asthma have been increasing, ${ }^{11}$ and mortality from all other causes of "avoidable" mortality has been declining sharply in several countries, ${ }^{12}$ deaths from asthma seem to be a notable exception. It is almost inevitable that either the prevalence or severity of the disease is increasing, or that the management of asthma is having a deleterious effect on mortality from the disease.
Frost $^{13}$ was the first to describe a change in mortality in terms of change in risk from one generation (cohort) to another rather than in terms of calendar time (period), finding this a useful way to describe the decline in mortality from tuberculosis. Since then a large literature has accrued on "ageperiod-cohort" analysis. ${ }^{1415}$

Variation in mortality over time can be attributed to changes in the risk of death as subjects get older (age), changes due to the circumstances prevailing at the time of death (period), and changes that are associated with the generation to which subjects belong (cohort). Period effects have their origin in factors operating around the time of death and these may include methods of classifying cause of death, ${ }^{16}$ medication ${ }^{17}$ where this has a short term effect, acute infectious epidemics $^{18}$ or increased exposure to allergens. ${ }^{19}$ Cohort effects on the other hand are more difficult to interpret. Though they are clearly determined by the year of birth they include a number of factors related to environment and lifestyle to which individuals may not be exposed until some years later. Examples include cigarette smoking, where habits are related to year of birth but where the habit is not generally acquired until adolescence. Because of the close association between these three elements there is no entirely satisfactory method of ascribing a consistent increase or decrease in mortality over time to an effect of either period or cohort. ${ }^{20}$ In spite of this, analysis can produce some useful evidence from which limited but valid conclusions may be drawn. ${ }^{21}$ 


\section{Methods}

Age specific asthma deaths and population estimates were taken from the report of the General Registrar's Office (GRO) ${ }^{22}$ or Office of Populations Censuses and Surveys (OPCS) ${ }^{23}$ for the years 1931-85. Rates were estimated for the civil population for most years, but the civil and military populations were combined for males from 1940 to 1949 and for females from 1941 to 1949. The ICD codes used were ICD-4:112, ICD5:112.6, ICD-6:241, ICD-7:241, ICD-8:493 and ICD-9:493. Deaths were analysed for six 5-year age groups between 5-9 and 30-34 years and for eleven 5-year periods of calendar time from 1931-35 to 1981-85. These groups represented 16 cohorts of subjects with mid-year of birth at 5-year intervals beginning in 1901.

Logistic regression using the program $\mathrm{GLIM}^{24}$ was used to estimate the age, cohort and period effects on mortality. Because of evident overdispersion of the residuals, extra-binomial variation was taken into account using the method suggested by Pocock et al. ${ }^{25}$ The significance of effects was estimated from the residual sums of squares of different models after first subtracting the estimated sampling variance (Pocock et al's $\tau^{2}$ ).

There was no significant difference between the effect of birthdate (cohort) on mortality for the two sexes, and this effect was therefore assumed to be the same for each sex. This reduction in the number of parameters in the model did not however lead to a unique solution to the regression analysis as has been suggested. ${ }^{26}$ This was achieved by analysing the 16 cohort values as eight pairs of values representing cohorts born in ten year bands starting in 1899-1908. This is a greater reduction in parameters than is required to produce a unique solution to the regression, but combining pairs through the whole range of cohort values is less likely to produce extreme estimates of the linear trends than if only one pair of values is combined in the analysis. Broader definition of the cohorts also reduces the effect of biases due to misclassification which may be a serious source of error in this type of analysis. ${ }^{27}$

\section{Results}

Figure 1 and table 1 show the age standardised and age specific mortality rates from asthma for males and females aged 5-34 for the years 1931-85. With the exception of the increase in mortality in the 1960s, mortality rates remained fairly constant throughout this period, though the higher mortality among females in the years before 1960 was replaced by a male preponderance thereafter. The increase in mortality noted in the 1960s is otherwise the only remarkable feature. There were no large changes in mortality associated with the changes in ICD.

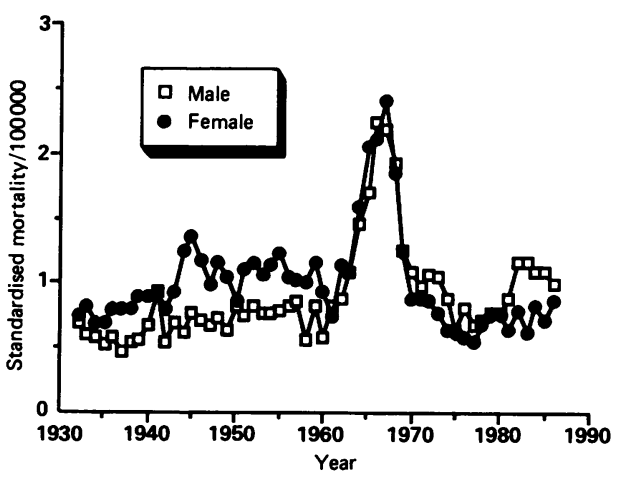

Fig 1 Age standardised mortality from asthma among 5-34 year olds in England and Wales 1931-1985.

Table 1 Asthma deaths/100 000 population in England and Wales 1931-85

\begin{tabular}{|c|c|c|c|c|c|c|}
\hline & \multicolumn{6}{|c|}{ Age (years) } \\
\hline & $5-9$ & $10-14$ & $15-19$ & $20-24$ & $25-29$ & $30-34$ \\
\hline \multicolumn{7}{|l|}{ Male } \\
\hline $1931-35$ & 0.35 & 0.22 & 0.20 & 0.42 & 0.65 & $1 \cdot 26$ \\
\hline $1936-40$ & 0.31 & 0.23 & 0.22 & 0.40 & 0.79 & 1.39 \\
\hline $1941-45$ & 0.32 & 0.28 & 0.28 & 0.53 & 0.79 & $1 \cdot 30$ \\
\hline $1946-50$ & 0.21 & $0 \cdot 28$ & 0.55 & 0.69 & 0.91 & $1 \cdot 20$ \\
\hline $1951-55$ & 0.14 & 0.36 & 0.82 & 0.82 & 0.92 & $1 \cdot 24$ \\
\hline $1956-60$ & 0.31 & 0.37 & 0.44 & 1.04 & 0.84 & 0.91 \\
\hline $1961-65$ & 0.44 & 1.46 & $1 \cdot 30$ & 1.46 & 1.65 & 2.08 \\
\hline $1966-70$ & 0.58 & 1.71 & 1.66 & $1 \cdot 26$ & 1.52 & 1.66 \\
\hline 1971-75 & 0.27 & 0.78 & 0.93 & 0.92 & $1 \cdot 01$ & 0.91 \\
\hline $1976-80$ & 0.22 & 0.61 & 0.76 & 0.67 & 0.86 & 0.97 \\
\hline $1981-85$ & 0.21 & 0.92 & $1 \cdot 18$ & 1.22 & $1 \cdot 39$ & $1 \cdot 19$ \\
\hline \multicolumn{7}{|l|}{ Female } \\
\hline $1931-35$ & 0.35 & 0.07 & 0.30 & 0.66 & $1 \cdot 13$ & 1.55 \\
\hline $1936-40$ & 0.45 & 0.28 & 0.33 & 0.74 & 1.26 & 1.65 \\
\hline $1941-45$ & 0.33 & 0.27 & 0.53 & $1 \cdot 10$ & 1.52 & $2 \cdot 40$ \\
\hline $1946-50$ & 0.32 & 0.31 & 0.83 & 1.05 & $1 \cdot 33$ & 1.91 \\
\hline $1951-55$ & 0.26 & 0.31 & 0.86 & 1.48 & 1.43 & 1.97 \\
\hline $1956-60$ & 0.24 & 0.38 & 0.94 & $1 \cdot 19$ & 1.20 & 1.43 \\
\hline $1961-65$ & 0.29 & 1.02 & $1 \cdot 33$ & 1.81 & $2 \cdot 20$ & $2 \cdot 51$ \\
\hline $1966-70$ & 0.28 & 1.21 & 1.44 & 1.60 & 1.71 & 1.96 \\
\hline $1971-75$ & 0.14 & 0.31 & 0.76 & 0.83 & 0.60 & 1.02 \\
\hline $1976-80$ & $0 \cdot 20$ & 0.44 & 0.67 & 0.74 & 0.72 & 0.78 \\
\hline $1981-85$ & 0.19 & 0.47 & 0.89 & 0.97 & 0.92 & 0.64 \\
\hline
\end{tabular}

There was no significant linear increase or decrease in mortality rates over this period as a whole. The cohort effects for males and females were not significantly different, though the effects of period and age were different in the two sexes. The residuals of the final model which took the extra-binomial variation into account ${ }^{25}$ were normally distributed. All the effects reported here were significant $(p<0.01)$ (table 2). 
Table 2 Estimates of significance of individually estimable effects from the final analysis of asthma mortality

\begin{tabular}{|c|c|c|c|c|c|}
\hline Effect & $\begin{array}{l}\text { Non-sampling } \\
\text { residual } \\
\text { sum of squares }\end{array}$ & $d f$ & $\begin{array}{l}\text { Mean sum } \\
\text { of squares }\end{array}$ & $F$ & $(n 1, n 2)$ \\
\hline $\begin{array}{l}\text { Due to complete } \\
\text { model }^{\mathrm{a}}\end{array}$ & e 62.892 & 38 & 1.655 & $17.59 t$ & $(38,93)$ \\
\hline $\begin{array}{l}\text { Due to cohort } \\
\text { effect }\end{array}$ & 2.732 & 7 & 0.39 & $4 \cdot 14^{*}$ & $(7,93)$ \\
\hline $\begin{array}{l}\text { Due to age-sex } \\
\text { interaction }\end{array}$ & 1.582 & 5 & 0.32 & $3 \cdot 37^{*}$ & $(5,93)$ \\
\hline $\begin{array}{l}\text { Due to period-se } \\
\text { interaction }\end{array}$ & ${ }_{2.742}$ & 10 & 0.27 & $2.92^{*}$ & $(10,93)$ \\
\hline Residual & 8.748 & 93 & 0.09 & & \\
\hline
\end{tabular}

* $p<0.01 ; \dagger p \ll 0.001 ;{ }^{a}$ Includes age, sex, period and cohort and age-sex and period-sex interactions.

The independent estimates of age, cohort and period effects for each sex are shown in figs $2-4$. The effects shown in each case are log odds of the mortality

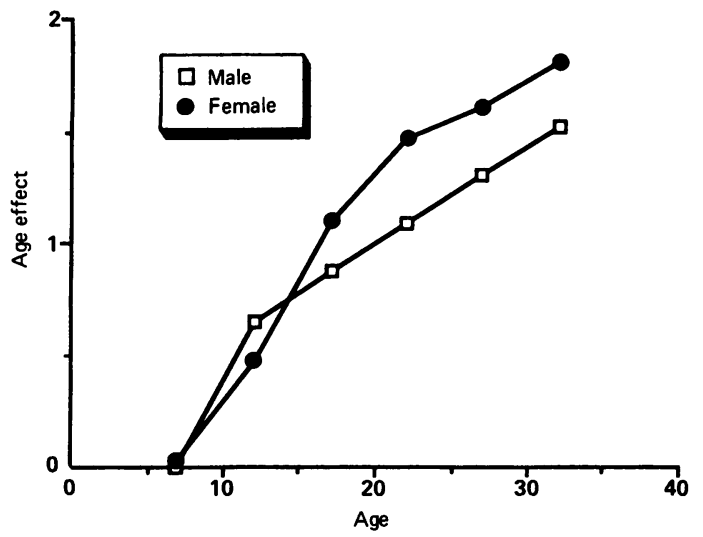

Fig 2 The effect of "age" on asthma mortality 1931-85 after taking account of the effects of "period" and "cohort".

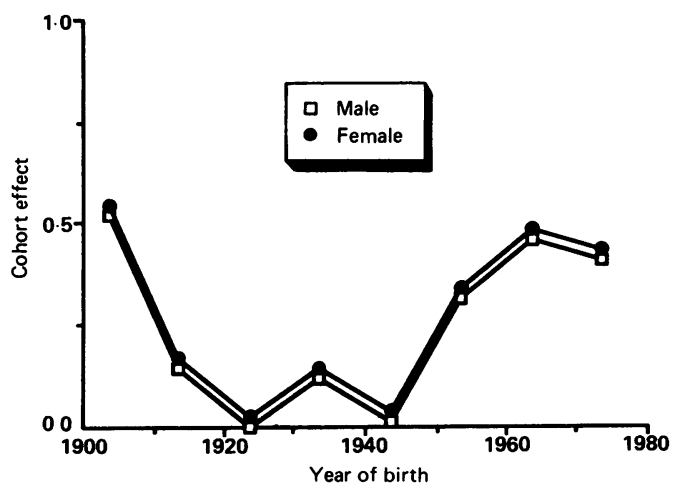

Fig 3 The effect of "cohort" on asthma mortality 1931-85 after taking account of the effects of "age" and "period".

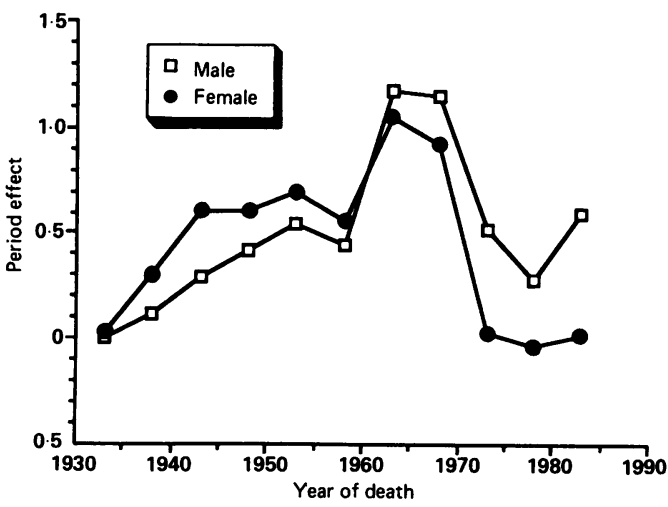

Fig 4 The effect of "period" on asthma mortality 1931-85 after taking account of the effects of "age" and "cohort".

rate compared to a standard group where the value is set arbitrarily at zero. The standard groups are males aged 5-9 years, males dying in 1931-5, and males born in 1919-28. Mortality rose sharply with age, slowing down markedly among men at adolescence but continuing to rise rapidly among the women and showing a marked female preponderance from adolescence onwards. Cohort values show declining values for those born from the early part of the century until the 1920s and then relatively constant values up until the 1940s. From the 1950s to the early 1980s however they show an increase. Period values, on the other hand, show a steady increase in the period from 1931 to the 1960s followed by a sharp increase in the 1960 s and a sharp decline in the 1970s. This is followed by a further increase among the males and a further slight fall among the females. The small female preponderance of deaths in the 1930s, ' 40 s and ' 50 s is replaced by an increasing male preponderance thereafter. Period effects are equivalent to changes in death rate by calendar time (fig 1) after standardising for age effects and cohort effects.

\section{Discussion}

What at first appears to be an unremarkable distribution of asthma mortality over time, with the exception of a sudden but short lived increase in the 1960 s, turns out to be more complex when analysed to take account of age, period and cohort effects. In the early part of the period succeeding generations have lower mortality while the period effect is increasing. In the latter part of the period successive cohorts have increased mortality while the period effect is declining.

The principal difficulty with the interpretation of "age-period-cohort" analysis is that a linear change in mortality over time cannot be attributed to either a 
"period" or "cohort" effect with any certainty. As can be seen from fig 1 there is no such linear trend in these data, but this does not exclude the possibility of two linear trends for period and cohort effects going in opposite directions. For this reason, although a number of solutions have been proposed for the problem of orienting the cohort, period and age trends, ${ }^{28}{ }^{29}$ none of these are satisfactory in the sense of providing an orientation that is valid and that does not rely on some outside criterion. However, the shapes of the curves are estimable and fixed once the model parameters have been reduced. Some useful and valid conclusions can be drawn from this information alone. To start with it is clear that there are both cohort and period effects of major importance. The sharpest changes in the cohort effect came between the subjects born in the 1920s and 1940s when a relative downward trend in mortality in succeeding cohorts changed to a relative upward trend. The major change in the period effect occurred as would have been expected in the 1960s, though for men there is a further sharp change in direction in the 1970s. It is perhaps surprising that the increasing trend in the effect of period from the 1930s to the 1960 s is as uniform as it appears. This has not been remarked on before, perhaps because it has been obscured by the fall in mortality between succeeding cohorts born between 1901 and 1930 (fig 3).

It is not possible from the data given here to determine the reasons for the changes in mortality rates, but the analysis does show that the changes that have occurred are more complex than have been shown previously. The increasing mortality in cohorts born since the 1940s strongly suggests an increasing prevalence of the condition and is unlikely to be due to any change in the method of reporting asthma deaths. Some support for this view comes from other sources suggesting an increase in the prevalence of atopic disease.

Local studies in both England ${ }^{30}$ and New Zealand ${ }^{31}$ have shown increases in asthmatic symptoms among school children in the years since the Second World War. Local changes in population between the surveys make these studies hard to interpret, but in the United States, where there has also been an increase in recorded mortality from asthma and where there are national data on prevalence, the proportion of subjects aged 6-11 years old who were reported to have a diagnosis of asthma rose from 48/1000 in $1971-4$ to $76 / 1000$ in $1976-80(p<0.01){ }^{32}$ The interpretation of these figures is again not straightforward as all studies relying on the reported prevalence of a diagnosed condition are vulnerable to changes in diagnostic fashion. Furthermore the precise formulation of the questions changed between the surveys, and there was no comparable increase in asthma mortality among 12-17 year olds, with the possible exception of an increase among black youths.

The age-standardised proportion of the population receiving treatment for asthma in selected general practices in England and Wales also increased between $1970 / 1$ and $1981 / 2$ from $11 \cdot 6 / 1000$ to $20 \cdot 5 / 1000$ in men and from $8 \cdot 8 / 1000$ to $15 \cdot 9 / 1000$ in women. ${ }^{33}$ The first born offspring of a cohort of children studied in the National Perinatal Survey of 1946 were three times more likely than their parents to receive treatment for asthma before their fifth birthday. ${ }^{34}$ However, all these increases may have been due to changes in treatment as much as to changes in the prevalence of disease.

Other atopic conditions have also apparently increased in prevalence over the same period. The period prevalence of patients consulting GPs for hay-fever in selected practices in England and Wales increased between $1970 / 1$ and $1981 / 2$ from $10 \cdot 8$ to $19 \cdot 8$ per thousand in men and from 10.3 to 19.7 per thousand in women. ${ }^{33}$ Eczema was also increasingly common as a diagnosis in the three national cohorts of children born in 1946, 1958 and 1970, as well as in other prevalence surveys done over the same period. ${ }^{35}$

Finally the distribution of skin sensitivity to common allergens by age is compatible with the presence of a cohort effect, showing an initial increase with age followed by a decline. ${ }^{36} 37$ This pattern of morbidity is compatible with an evolving increase in morbidity in subsequent cohorts which produces higher rates in the younger age groups who also belong to the later cohorts. Barbee et al in Arizona ${ }^{37}$ have recently reported on a longitudinal study showing that the prevalence of skin sensitivity increases with age at all ages, though the increase is much more marked in the younger age groups. This suggests that the secondary decline in prevalence with age seen in cross sectional data may indeed be an artefact caused by a cohort effect.

The analysis reported in this paper implies that the recent increase in asthma mortality is not principally an artefact due to increased reporting, a change that would appear as an increase in the period rather than the cohort effect. It is also unlikely to be due to any adverse effects of treatment for the same reason. The systematic increase in mortality in subsequent cohorts, at least up until those born in the early 1960s, implies that changing mortality rates are probably due to an increase in the prevalence of the condition, and evidence from other studies, though not compelling, would support this conclusion.

I would like to thank Dr A V Swan, Miss S Chinn and Mr D G Cook for discussions on some of the general problems of this analysis and $\mathrm{Mr} \mathrm{T} \mathrm{D}$ Jones and Miss $\mathrm{S}$ Chinn for assistance with some aspects of 
programming. I would like to thank Professor Haroutune Armenian for reading an earlier draft and making some useful suggestions for its improvement.

\section{References}

${ }^{1}$ Khot A, Burn R. Deaths from asthma (letter). Br Med J 1984; 289: 557.

2 Burney PGJ. Asthma mortality in England and Wales: evidence for a further increase, 1974-84. Lancet 1986; ii 323-6.

${ }^{3}$ Burr ML. Is asthma increasing? J Epidemiol Community Health 1987; 41: 185-9.

${ }^{4}$ Stewart CJ, Nunn AJ. Are asthma mortality rates changing? Br J Dis Chest 1985; 79: 229-34.

${ }^{5}$ Markowe HLJ. Asthma mortality in England and Wales (letter). Lancet 1986; ii: 636.

${ }^{6}$ Alderson M. Trends in morbidity and mortality from asthma Population Trends 1987; 49: 18-23.

${ }^{7}$ Bousquet J, Hatton F, Godard P, Michel FB. Asthma mortality in France. J Allergy Clin Immunol 1987; 80: 389-94.

${ }^{8}$ Sears MR, Beaglehole R. Asthma morbidity and mortality in New Zealand. J Allergy Clin Immunol 1987; 80: 383-8.

${ }^{9}$ Evans R. Recent advances reflecting increases in mortality from asthma. $J$ Allergy Clin Immunol 1987; 80: 377-9.

${ }^{10}$ Rutstein D, Berenberg W, Chalmers T et al. Measuring the quality of medical care: a clinical method. New Eng J Med 1976; 294: 582-8.

${ }^{11}$ Keating G, Mitchell EA, Jackson R, Beaglehole R, Rea H. Trends in sales of drugs for asthma in New Zealand, Australia and the United Kingdom 1975-81. Br Med J 1984; 289: 348-51.

12 Charlton J, Velez R. Some international comparisons of mortality amenable to medical intervention. $\mathrm{Br}$ Med $J$ 1986; 292: 295-301.

${ }^{13}$ Frost WH. The age selection of mortality from tuberculosis in successive decades. Am J Hyg. 1939; 30: 91-6.

14 Clayton D, Schifflers E. Models for temporal variation in cancer rates. I: Age-period and Age-cohort models. Statistics in Medicine 1987; 6: 449-67.

15 Clayton D, Schifflers E. Models for temporal variation in cancer rates. II: Age-period-cohort models. Statistics in Medicine 1987; 6: 469-81.

${ }^{16}$ Esdaile JM, Feinstein AR, Horwitz RI. A reappraisal of the United Kingdom epidemic of fatal asthma. Arch Intern Med 1987; 147: 543-9.

17 Inman W, Adelstein A. Rise and fall of asthma mortality in England and Wales in relation to use of pressurised aerosols. Lancet 1969; ii: 279-85.

18 Williams DA. Deaths from asthma in England and Wales. Thorax 1953; 8: $137-40$.

19 Jenkins PF, Mullins J, Davies BH, Williams DA. The possible role of aero-ellergens in the epidemic of asthma deaths. Clin Allergy 1981; 11: 611-20.
${ }^{20}$ Kupper LL, Janis JM, Karmous A, Greenberg BG. Age-period-cohort analysis: a review and critique. $J$ Chron Dis 1984; 38: 811-30.

${ }^{21}$ Holford TR. An alternative approach to statistical ageperiod-cohort analysis. J Chron Dis 1984; 38: 831-40.

22 The Registrar-General's Statistical Review of England and Wales for the years 1931 to 1973. London: HMSO, 1932-1976.

${ }^{23}$ Office of Population Censuses and Surveys. Mortality Statistics-Cause series DH2 1-12 (1974-85). London: HMSO, 1977-1987.

${ }^{24}$ Baker RJ, Nelder JA. The GLIM System: Release 3. Oxford: NAG, 1981.

25 Pocock SJ, Cook DG, Beresford SAA. Regression of area mortality rates on explanatory variables: what weighting is appropriate? Appl Statistics 1981; 30: 286-95.

${ }^{26}$ Day NE, Charnay B. Time trends, cohort effects, and ageing as influence on cancer incidence. In Magnus $\mathbf{K}$, ed. Trends in cancer incidence, causes and practical implications. New York: Hemisphere Publishing Corp, 1982.

${ }^{27}$ Rogers WL. Estimable functions of age period and cohort effects. Amer Sociol Rev 1982; 47: 774-87.

${ }^{28}$ Osmond C, Gardner MJ. Age period and cohort models applied to cancer mortality rates. Statistics in Medicine 1982; 1: 245-59.

${ }^{29}$ Robertson C, Boyle P. Age period and cohort models: the use of individual records. Statistics in Medicine 1985; 5: 527-38.

${ }^{30}$ Smith JM. The prevalence of asthma and wheezing in children. Br J Dis Chest 1976; 70: 73-7.

${ }^{31}$ Mitchell EA. Increasing prevalence of asthma in children. NZ Med J 1983; 96: 463-4.

32 Gergen PJ, Mullally DI, Evans R. National Survey of prevalence of asthma among children in the United States, 1976-80. Pediatrics 1988; 81: 1-7.

33 Fleming DM, Crombie DL. Prevalence of asthma and hay fever in England and Wales. Br Med J 1987; 293: 279-83.

${ }^{34}$ Wadsworth $M$. Intergenerational differences in child health. In: British Society for Population Studies. Measuring socio-demographic change. London: OPCS, 1985.

${ }^{35}$ Taylor B, Wadsworth M, Wadsworth J, Peckham C. Changes in Reported prevalence of eczema since the 1939-45 war. Lancet 1984; ii: 1255-7.

${ }^{36}$ Burney PGJ, Britton JR, Chinn S, et al. Descriptive epidemiology of bronchial reactivity in an adult population: results from a community study. Thorax 1987; 42: 38-44.

${ }^{37}$ Barbee R, Kaltenborn W, Lebowitz M, Burrows B. Longitudinal changes in allergen skin test reactivity in a community population sample. $J$ Allerg Clin Immunol 1987; 79: 16-24. 